\title{
Development of a Robust PET-RAFT Polymerization Using Graphitic Carbon Nitride $\left(\mathrm{g}-\mathrm{C}_{3} \mathrm{~N}_{4}\right)$
}

\author{
Qiang Fu', Qiushi Ruan ${ }^{\mathrm{b}}$, Thomas G. McKenzie ${ }^{\mathrm{a}}$, Amin Reyhani ${ }^{\mathrm{a}}$, Junwang Tang ${ }^{\mathrm{b} *}$ and Greg G. Qiao ${ }^{\mathrm{a} *}$

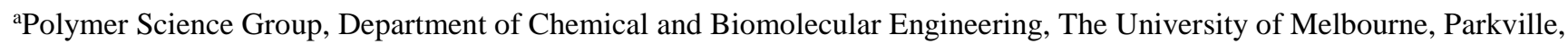 \\ VIC 3010, Australia.

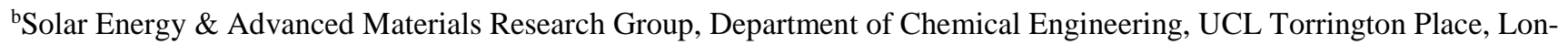 \\ don, WC1E 7JE (UK)
}

KEYWORDS: graphitic carbon nitride, RAFT photopolymerization, oxygen tolerance, photoinduced electron transfer.

\begin{abstract}
The metal-free semiconductor, graphitic carbon nitride $\left(\mathrm{g}-\mathrm{C}_{3} \mathrm{~N}_{4}\right)$, was introduced into RAFT polymerization for the first time. The production of linear polyacrylate and polyacrylamide has been achieved via PET-RAFT polymerization using g$\mathrm{C}_{3} \mathrm{~N}_{4}$ as a photoactive organocatalyst without prior deoxygenation. The resulting polymers display controlled molecular weights, narrow polymer dispersities, and high end-group fidelity as exemplified by ${ }^{1} \mathrm{H}$ NMR analysis, MALDI-TOF-MS measurement and chain extension experiment. Temporal control is illustrated by intermittent light and dark cycles, with polymer growth arrested in the absence of irradiation. The effects of changing RAFT agents (i.e. trithiocarbonates), solvents, catalyst concentrations and degrees of polymerization in this system have been investigated. The successful polymerization of non-purified monomer (i.e. still containing radical inhibitors) demonstrates the robust nature of the presented PET-RAFT system.
\end{abstract}

\section{INTRODUCTION}

Controlled reversible-deactivation radical polymerizations (RDRPs) have been known to suffer from severe oxygen inhibition, since the molecular oxygen can scavenge active radicals to produce unreactive peroxide radicals. ${ }^{1}$ Additionally, for photo-mediated RDRPs oxygen is known to quench the photoexcited state of employed photo-initiators/sensitizers, thereby inhibiting the reaction via photochemical deactivation. ${ }^{1}$ Over the last decade, the developments of oxygen tolerant RDRPs have attracted considerable attention. ${ }^{2-14}$ Different from conventional physical deoxygenation methods (i.e. freeze-pumpthaw cycles or bubbling inert gases), these RDRPs were successfully conducted by introducing reducing agents into the polymerization system to minimize the oxygen level. For example, the uses of tin(II) 2-ethylhexanoate $\left(\mathrm{Sn}(\mathrm{EH})_{2}\right)$, sodium ascorbate/ascorbic acid ${ }^{2,15}$ and zero valent metals (i.e. $\mathrm{Cu}$ and $\mathrm{Fe})^{3,16}$ allowed for the controlled RDRPs of various monomers through various modified copper-catalysed controlled radical polymerizations (CRPs). Boyer's group has reported the utilization of zinc tetraphenylporphyrin (ZnTPP) ${ }^{17}$, Ir/Ru-based photoredox catalysts ${ }^{6,18}$ or dyes ${ }^{19}$ to efficiently mitigate oxygen inhibition and to facilitate reversible additionfragmentation chain transfer (RAFT) polymerizations through a photo-induced electron/energy transfer (PET) process. However, the involvement of metal catalysts would result in potential contamination on the prepared polymers. A bioinspired system employing an enzyme (glucose oxidase, GOx) ${ }^{5}, 20$ which can eliminate oxygen from the reaction media was reported to facilitate RAFT polymerization without physical degassing. However, the high molecular weight of GOx (> 70 $\mathrm{kDa}$ ) may lead to complicated and costly purification protocols to remove the enzyme from the final products. Boyer et al. have reported an energy storage RDRP system where polymerization was initiated using hydroxyl radicals generated from the consumption of oxygen under visible light irradiation in the presence of photo-organocatalyst and ascorbic acid. ${ }^{12}$ Our group has recently developed a Fenton RAFT system and achieved rapid and oxygen tolerant polymerizations of acrylamide through this system. ${ }^{14}$ Nevertheless, due to the low solubility of the co-catalysts (i.e. ascorbic acid or iron ions) in non-polar solvents, these technologies are limited to aqueous systems. Recently, Zhu and co-workers have reported that part of the radicals generated by photolysis of the xanthate (RAFT agent) could react with dissolved oxygen and form oxidative products. ${ }^{8}$ Thus, the polymers obtained in the presence of small amount oxygen showed higher molecular weights than expected. We have reported our new discovery that conventional RAFT agents can facilitate oxygen removal and subsequence controlled polymerization through an electron transfer (ET) pathway under blue light irradiation with a tertiary amine as cocatalyst. ${ }^{13}$

Graphitic carbon nitride $\left(\mathrm{g}-\mathrm{C}_{3} \mathrm{~N}_{4}\right)$ is a family of carbon nitride compounds with a generalized formula $\mathrm{C}_{3} \mathrm{~N}_{4}{ }^{21}$ Due to their semiconductor properties as well as other advantages such as facile synthesis, appealing electronic band structure, high physicochemical stability and "earth-abundant" nature, graphitic carbon nitrides have drawn broad interdisciplinary attention as a metal-free and visible-light-responsive photocatalyst in the area of solar energy conversion and environmental remediation. ${ }^{22-26}$ In addition, g- $\mathrm{C}_{3} \mathrm{~N}_{4}$ has been demonstrated to activate free radical $^{27,28}$ or copper-catalysed $\mathrm{CRP}^{28}$ via $\mathrm{ET}$ processes to generate reactive species. Although various semiconductors have been employed in copper-catalysed CRPs of methacrylates, ${ }^{26}$ there are few studies reporting the controlled RDRP of acrylates based on semiconductor 

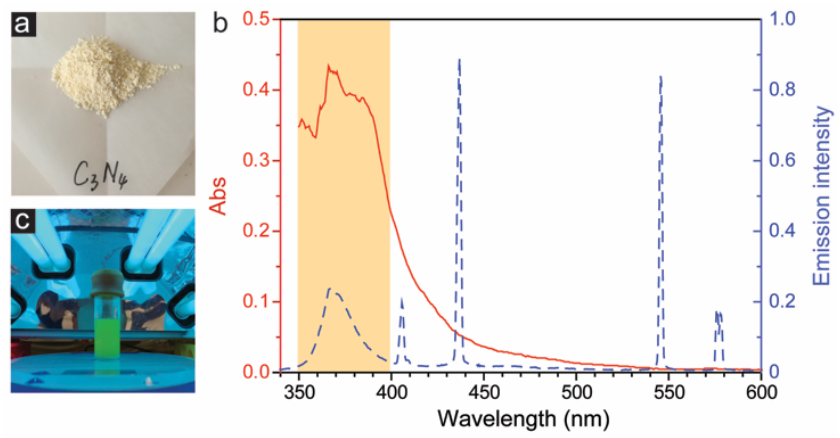

d

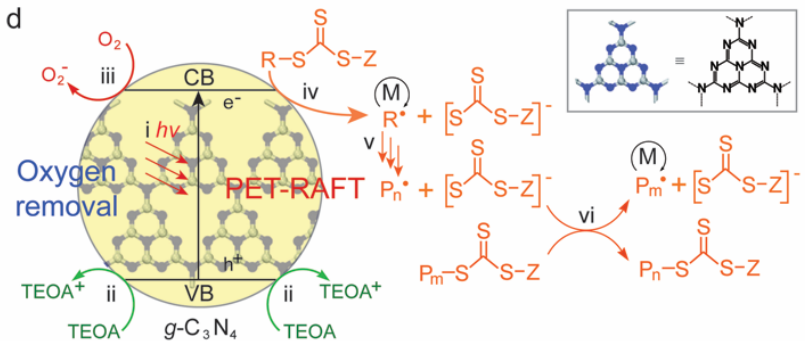

Figure 1. (a) Digital image of the graphitic carbon nitride (g$\mathrm{C}_{3} \mathrm{~N}_{4}$ ), (b) the UV-vis absorption spectrum of $\mathrm{g}-\mathrm{C}_{3} \mathrm{~N}_{4}$ (red) and the UV light source emission (blue), (c) digital image of the reaction setup, and (d) the proposed mechanisms for deoxygenation and PET-RAFT polymerization using $\mathrm{g}-\mathrm{C}_{3} \mathrm{~N}_{4}$ : (i) photo-activation of g- $\mathrm{C}_{3} \mathrm{~N}_{4}$, (ii-iv) ETs from amine to $\mathrm{g}-\mathrm{C}_{3} \mathrm{~N}_{4}$, from $\mathrm{g}-\mathrm{C}_{3} \mathrm{~N}_{4}$ to $\mathrm{O}_{2}$, and from $\mathrm{g}-\mathrm{C}_{3} \mathrm{~N}_{4}$ to TTC respectively, (v) initiation and chain propagation, and (vi) chain transfer (RAFT process).

photo-catalysis. More importantly, the reduction and oxidation potential of a semiconductor photocatalyst are crucial for the oxygen-mediated polymerisation process. More negative the conduction band (CB), higher activity the oxygen capture process. The $\mathrm{g}-\mathrm{C}_{3} \mathrm{~N}_{4}$ has a $\mathrm{CB}$ edge of $-1.2 \mathrm{eV}$ vs. NHE, which is much more negative than the majority of the reported photocatalysts. On the other hand, a less positive valence band (VB) is beneficial for the polymerisation as the photo-generated hole will not decompose the prepared polymer. Consistent with the requirement, $\mathrm{g}-\mathrm{C}_{3} \mathrm{~N}_{4}$ has a $\mathrm{VB}$ edge at $\sim 1.5 \mathrm{eV} v s$. NHE, quite moderate oxidation potential. ${ }^{29,}{ }^{30}$ Given such interesting intrinsic property of $\mathrm{g}-\mathrm{C}_{3} \mathrm{~N}_{4}$, an oxygen tolerant photo-controlled RDRP with broader monomer utility by introducing $\mathrm{g}-\mathrm{C}_{3} \mathrm{~N}_{4}$ into a RAFT system has been developed for the first time in the study.

\section{EXPERIMENTAL SECTION}

\section{Materials}

1-dodecanethiol (>98\%), benzyl bromide (anhydrous, 99.8\%), hydrochloric acid $(\mathrm{HCl}, 37 \%)$, carbon disulfide $\left(\mathrm{CS}_{2}\right.$, anhydrous, $\geq 99 \%$ ), potassium hydroxide $(\mathrm{KOH})$, sodium sulfate ( $\mathrm{Na}_{2} \mathrm{SO}_{4}$, anhydrous 99\%) 2-cyano-2-propyl dodecyl trithiocarbonate (TTC-2, 97\%), 2-(((butylthio)-carbonothiolyl)thio) propanoic acid (TTC-3), 2-cyano-2-propyl benzodithioate (> 97\%), trans-2-(3-(4-tert-bbutylphenyl)-2-methyl-2-propenylidene)-malononitrile (DCTB, 98\%), sodium trifluoroacetate (NaTFA, >99\%) and triethanolamine (TEOA, 99\%) were purchased from Sigma-Aldrich and used as received. Monomers methyl acrylate (MA, 99\%, Aldrich), butyl acrylate (BA, $>99 \%$, Aldrich) and N,N-dimethylacrylamide (DMA, 99\%, Aldrich) were passed over basic alumina to remove inhibitors prior to use. Deuterated chloroform $\left(\mathrm{CDCl}_{3}, 99.8 \%\right)$ and dimethyl sulfoxide (DMSO- $d_{6}, 99.9 \%$ ) were purchased from Cambridge Isotope Laboratories, Inc. AR grade methanol, ethanol, dimethyl sulfoxide (DMSO), toluene and other solvents were purchased from Chem-Supply Pty. Ltd. and used without further purification. UV light sourceused for all experiments was a commercial nail-curing lamp ('Beaufly-nail lamp', 220V) fitted with $4 \times 9 \mathrm{~W}$ bulbs with $\lambda_{\max } \sim 365 \mathrm{~nm}\left(3.5 \mathrm{~mW} / \mathrm{cm}^{2}\right)$.

\section{Characterizations}

Gel-Permeation Chromatography (GPC): GPC for THF mobile phase was conducted using a Shimadzu system fitted with a Wyatt DAWN DSP multi-angle laser light scattering detector $(690 \mathrm{~nm}, 30 \mathrm{~mW})$ and a Wyatt OPTILAB EOS interferometric refractometer $(690 \mathrm{~nm})$. THF was used as the eluent with three Phenomenex phenogel columns $(500,104,106 \AA$ porosity $5 \mu \mathrm{m}$ bead size) operated at $1 \mathrm{~mL}$ per minute at a column temperature of $45^{\circ} \mathrm{C}$. To process the GPC data, the program 'Astra' by Wyatt technologies was used. All samples were filtered through $0.45 \mu \mathrm{m}$ nylon filters prior to injection. The polydimethyl acrylamides were analyzed by aqueous GPC using an eluent of Milli-Q water with 0.1 vol\% trifluoroacetic acid (TFA). The system was operated at a flow rate of $1 \mathrm{~mL} \mathrm{~min} \mathrm{~m}^{-1}$ at $25^{\circ} \mathrm{C}$. A Shimadzu Liquid Chromatography system was utilized, equipped with a Shimadzu RID-10 refractometer $(\lambda=633 \mathrm{~nm})$ and Wyatt 3-angle light scattering detector, with three Waters Ultrahydrogel columns in series ((i) $250 \AA$ porosity, $6 \mu \mathrm{m}$ diameter bead size; (ii) and (iii) linear, $10 \mu \mathrm{m}$ diameter bead size) for separation. The $\mathrm{dn} / \mathrm{dc}$ values of PDMA in the above eluent was calculated to be $0.190 \mathrm{~mL} \mathrm{~g}^{-1}$ at $25{ }^{\circ} \mathrm{C}$ using a method of $100 \%$ mass recovery on a sample prepared from isolated PDMA to an accurate concentration.

Nuclear Magnetic Resonance (NMR) Spectroscopy: ${ }^{1} \mathrm{H}$ NMR spectroscopy and ${ }^{13} \mathrm{C}$ NMR spectroscopy were conducted on a Varian Unity $400 \mathrm{MHz}$ spectrometer operating at $400 \mathrm{MHz}$, using the solvents deuterated chloroform $\left(\mathrm{CDCl}_{3}\right)$ or dimethyl sulfoxide (DMSO- $d_{6}$ ) (Cambridge Isotope Laboratories) as reference and sample concentrations of approximately $10 \mathrm{mg} \cdot \mathrm{mL}^{-1}$.

Matrix-assisted laser desorption/ionization time of flight (MALDI-ToF) mass spectroscopy: MALDI-ToF MS was performed on a Bruker Autoflex III Mass Spectrometer operating in positive linear mode; the analyte, matrix (DCTB) and cationisation agent (NaTFA) were dissolved in THF at concentrations of 10,10 , and $1 \mathrm{mg} \mathrm{mL}^{-1}$, respectively, and then mixed in a ratio of $10: 1: 1$. Then $0.3 \mu \mathrm{L}$ of this solution was spotted onto a ground steel target plate and the solvent was allowed to evaporate prior to analysis. Flex Analysis (Bruker) was used to analyze the data.

Dynamic Light Scattering (DLS): DLS measurements were conducted on a Wyatt DynaPro NanoStar DLS/SLS instrument with a GaAs laser $(658 \mathrm{~nm})$ at an angle of $90^{\circ}$ and a temperature of $25 \pm 0.1{ }^{\circ} \mathrm{C}$. Stable spectra were determined at sample concentrations of $1 \mathrm{mg} \mathrm{mL}^{-1}$.

Scanning Electron Microscopy (SEM): SEM measurements were conducted on a Quanta FEG 200 ESEM. Samples were 
coated with a gold using a Dynavac Mini Sputter Coated prior to imaging.

$X$-ray photoelectron spectroscopy (XPS): XPS measurements were done on a Thermoscientific XPS K-alpha surface analysis machine using an Al source. Analysis was performed on the Thermo Advantage software.

Powder X-ray diffraction (PXRD): PXRD measurements were taken using a Bruker D4 diffractometer, a voltage of $40 \mathrm{kV}$, at $30 \mathrm{~mA}$, using a $\mathrm{Cu}$ source with $\mathrm{K} \alpha_{1}=1.540562$ and $\mathrm{K} \alpha_{2}=$ 1.544398 , accompanied by a nickel filter.

Ultraviolet-visible spectroscopy (UV-Vis): UV-Vis absorption spectra were collected using a Shimadzu UV-Vis 2550 spectrophotometer fitted with an integrating sphere.

Attenuated total reflection (ATR) Fourier transform infrared spectroscopy (ATR-FTIR): ATR-FTIR spectroscopy was performed on a Perkin-Elmer 1605 FT-IR spectrometer in the wavenumber range from $400-4000 \mathrm{~cm}^{-1}$ with a resolution of $0.5 \mathrm{~cm}^{-1}$.

Raman Spectroscopy: Raman spectroscopic measurements were performed on a Renishaw InVia Raman Microscope, using a $325 \mathrm{~nm}$ excitation laser, and a wavenumber range from $100-3000 \mathrm{~cm}^{-1}$

\section{Preparation of graphitic carbon nitride $\left(\mathrm{g}-\mathrm{C}_{3} \mathrm{~N}_{4}\right)$}

Graphitic carbon nitride was synthesised according to previous report. ${ }^{23}$ In a typical run, the precursor was put in a lidded high quality alumina crucible, then placed inside a muffle furnace and heated at a rate of $5 \mathrm{~min}^{-1}$ ), and finally held at a designated temperature of $600{ }^{\circ} \mathrm{C}$ for several hours. The resultant powders were then washed with water, $\mathrm{HCl}, \mathrm{NaOH}$ and once again with water to remove all unreacted and potentially detrimental surface species. The product was denoted as $\mathrm{g}-\mathrm{C}_{3} \mathrm{~N}_{4}$.

\section{Synthesis of benzyl dodecyl carbonotrithioate (TTC-1)}

TTC-1 was synthesized as previously reported. ${ }^{31}$ To a round bottom flask containing 1-dodecanethiol (2.92 g, $14.4 \mathrm{mmol})$ was added a solution of $\mathrm{KOH}(0.97 \mathrm{~g}, 17.3 \mathrm{mmol}$ in $40 \mathrm{~mL}$ of Milli-Q water), followed by the dropwise addition of carbon disulfide $(1.73 \mathrm{~mL}, 28.8 \mathrm{mmol})$. The colour of the solution mixture gradually turned yellow upon addition of carbon disulfide. The mixture was left to stir for $3 \mathrm{~h}$ at $25^{\circ} \mathrm{C}$ until the colour of the solution changed from yellow to orange. Subsequently, benzyl bromide $(1.72 \mathrm{~mL}, 14.4 \mathrm{mmol})$ was added to the reaction mixture and the solution was left to stir for another $24 \mathrm{~h}$ at $25^{\circ} \mathrm{C}$. By the end of the reaction, the colour of the solution became yellow. The crude product in the solution mixture was extracted with $\mathrm{CHCl}_{3}(40 \mathrm{~mL})$. Next, the organic phase was washed with $0.5 \mathrm{M} \mathrm{HCl}$ solution $(30 \mathrm{~mL})$, brine $(30$ $\mathrm{mL})$ and Milli-Q water $(30 \mathrm{~mL})$. The organic layer was dried over $\mathrm{Na}_{2} \mathrm{SO}_{4}$, filtered and concentrated in vacuo. The product was recrystallized from MeOH:EtOH $(1: 1,50 \mathrm{~mL})$ overnight at $-18{ }^{\circ} \mathrm{C}$ and recovered by filtration to afford the product as yellow crystals $(4.60 \mathrm{~g}$, yield $=86 \%) .{ }^{1} \mathrm{H}$ NMR $(400 \mathrm{MHz}$, $\left.\mathrm{CDCl}_{3}, \delta_{\mathrm{H}} \mathrm{ppm}\right): 7.36-7.25(\mathrm{~m}, 5 \mathrm{H}, \mathrm{Ar} \boldsymbol{H}), 4.61(\mathrm{~s}, 2 \mathrm{H}$, PhCH $\left.{ }_{2} \mathrm{~S}-\right)$, 3.37 (t, 2H, -SCH $\mathrm{CH}_{2-}$ ), 1.76-1.17 (m, 20H, -CH $\mathbf{H}_{2-}$ ), 0.89 (t, 3H, $\left.\left.\mathrm{CH}_{3^{-}}\right) .{ }^{13} \mathrm{C} \mathrm{NMR} \mathrm{(400} \mathrm{MHz,} \mathrm{CDCl}_{3}, \delta_{\mathrm{C}} \mathrm{ppm}\right)$ : 223.7, 135.1, 129.2, 128.6, 127.7, 41.3, 37.0, 31.9, 29.6, 29.6, $29.5,29.4,29.3,29.1,28.9,28.0,22.7,14.1$.

General procedure for PET-RAFT using $g-C_{3} N_{4}$ and TEOA
A vial glass (7 or $10 \mathrm{~mL}$ ) charged with $\mathrm{g}-\mathrm{C}_{3} \mathrm{~N}_{4}(5 \mathrm{mg})$, MA (0.905 mL, $10 \mathrm{mmol})$, TTC-1 (36.8 mg, $0.1 \mathrm{mmol})$, TEOA $(100 \mathrm{mg}, 0.67 \mathrm{mmol})$ and DMSO (50 vol \%) $([\mathrm{MA}] /[\mathrm{TTC}]=$ 100/1) was sealed with a rubber septa. The UV light source $\left(3.5 \mathrm{~mW} / \mathrm{cm}^{2}\right)$ was then switched "on" and the reaction mixture was stirred. Samples were taken at timed intervals via degassed syringe and immediately diluted with either $\mathrm{CDCl}_{3}$ or THF, for NMR and GPC analysis respectively.

\section{General procedure for chain extension experiment}

A $7 \mathrm{~mL}$ vial glass charged with $\mathrm{g}-\mathrm{C}_{3} \mathrm{~N}_{4}(5 \mathrm{mg})$, MA $(0.905$ $\mathrm{mL}, 10 \mathrm{mmol})$, TCT-1 (36.8 mg, $0.1 \mathrm{mmol})$, TEOA (100 mg, $6.7 \mathrm{mmol})$ and DMSO (50 vol \%) $([\mathrm{MA}] /[\mathrm{TCT}]=100 / 1)$ was sealed with a rubber septa. The UV light source $\left(3.5 \mathrm{~mW} / \mathrm{cm}^{2}\right)$ was then switched "on" and the reaction mixture was stirred. After 5 hours the conversion of MA achieves over $90 \%$ by ${ }^{1} \mathrm{H}$ NMR analysis. The mixture was precipitated into cold methanol and the resultant PMA was isolated by centrifugation and dried in vacuum at room temperature. A $7 \mathrm{~mL}$ vial glass charged with BA $(1.42 \mathrm{~mL}, 10 \mathrm{mmol})$, macro-TTC (PMA, $0.96 \mathrm{~g}, 0.1 \mathrm{mmol}), \mathrm{g}-\mathrm{C}_{3} \mathrm{~N}_{4}(5 \mathrm{mg})$, TEOA (100 mg, $\left.6.7 \mathrm{mmol}\right)$ and DMSO $(67$ vol \%) $([\mathrm{BA}] /[$ macro-TTC] $=100 / 1)$ was sealed with a rubber septa. The UV light source $\left(3.5 \mathrm{~mW} / \mathrm{cm}^{2}\right)$ was then switched "on" and the reaction mixture was stirred. After another 8 hours the conversion of BA achieves $94.9 \%$ by ${ }^{1} \mathrm{H}$ NMR analysis.

\section{“On/Off” reactions}

The "On"/"Off" reactions were set up in the same fashion, however at a given reaction time the UV light source (3.5 $\mathrm{mW} / \mathrm{cm}^{2}$ ) was turned off and the vial covered completely in aluminium foil and placed into a home-made 'dark box' for a designated time period. The polymerization was re-activated by irradiating the reaction mixture with UV light again. Samples were taken at timed intervals via degassed syringe and immediately diluted with either $\mathrm{CDCl}_{3}$ or THF, for NMR and GPC analysis respectively.

\section{RESULTS AND DISCUSSION}

In the present graphitic carbon nitride facilitated photoinduced electron transfer (PET) RAFT polymerization, g- $\mathrm{C}_{3} \mathrm{~N}_{4}$ was synthesized by urea hydrolysis and well-characterized by SEM, XRD, XPS and FT-IR measurements. The robust photoinduced catalytic ability of $\mathrm{g}-\mathrm{C}_{3} \mathrm{~N}_{4}$ was then demonstrated by a series of successful PET-RAFT polymerizations of acrylates and acrylamide without prior deoxygenation, leading to a novel PET-RAFT approach with lower toxicity, organic solvent tolerance and facile removal post-polymerization in comparison with aforementioned the previously reported oxygen tolerant RDRP systems.

The $\mathrm{g}-\mathrm{C}_{3} \mathrm{~N}_{4}$ prepared according to a previous reported procedure $^{23}$ shows light yellow colour (Figure 1a). We characterized the crystal structure of $\mathrm{g}-\mathrm{C}_{3} \mathrm{~N}_{4}$ by XRD, Raman and XPS measurements (Figure S1a) which confirm the successful formation of carbon nitride crystals. The dynamic light scattering (DLS) result indicates the dispersion quality $(\sim 5 \mu \mathrm{m})$ of the $\mathrm{g}$ $\mathrm{C}_{3} \mathrm{~N}_{4}$ crystals in dimethyl sulfoxide (DMSO) immediately after ultrasonication (inserted in Figure S1a). Other detailed characterizations on $\mathrm{g}_{-} \mathrm{C}_{3} \mathrm{~N}_{4}$, such as SEM and FT-IR are available in the Supporting Information (Figure S1 and S2). The UV light source used for all experiments is a commercial nail-curing lamp $\left(3.5 \mathrm{~mW} \mathrm{~cm}^{-2}\right)$. The peak emission $\left(\lambda_{\max }\right)$ from this light 

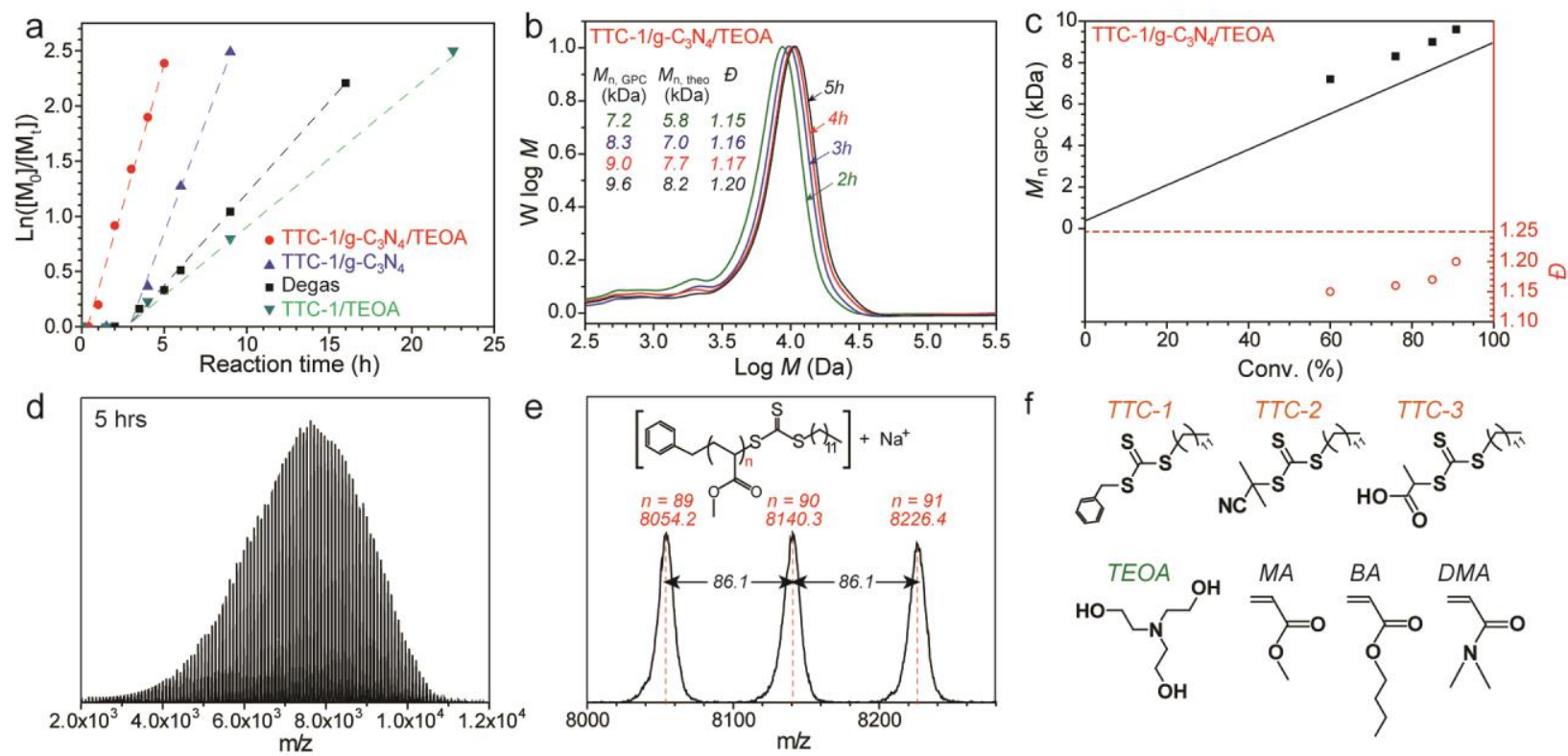

Figure 2. Characterization of PMA prepared by PET-RAFT polymerization without prior deoxygenation: (a) (c) kinetic study, (b) GPC evaluation, (c) number average molecular weight $\left(M_{\mathrm{n}}\right)$ and dispersity $(\nexists)$ data (the black line represents the theoretical molecular weight based on ${ }^{1} \mathrm{H}$ NMR analysis), and (d-e) MALDI-ToF-MS analysis. (f) Chemical structures of compounds investigated in this study. TTCs: benzyl dodecyl trithiocarbonate (TTC-1), 2-cyano-2-propyl dodecyl trithiocarbonate (TTC-2), and 2-(((butylthio)-carbonothiolyl)thio) propanoic acid (TTC-3); Amine: triethanolamine (TEOA); Monomers: methyl acrylate (MA), n-butyl acrylate (BA) and N,Ndimethylacrylamide (DMA).

source was measured to be $\sim 365 \mathrm{~nm}$, displaying clear emission-absorption overlap with the absorption band of $\mathrm{g}-\mathrm{C}_{3} \mathrm{~N}_{4}$ (Figure 1b).

PET-RAFT polymerization is an efficient approach to achieve controlled RDRPs of various monomers under relatively benign reaction conditions. ${ }^{32-34} \mathrm{We}$ have recently reported our discovery that trithiocarbonates (TTCs) are able to reduce oxygen by facilitating ET from tertiary amines (TAs, also known as co-catalyst) to oxygen under visible light irradiation. ${ }^{13}$ By taking advantage of this effect, we successfully conducted PET-RAFT polymerizations of acrylates without the requirement of pre-degassing the reaction mixtures. However, in this system the deoxygenation process takes $>3$ hours and the polymerization requires a total of 24 hours to achieve > $90 \%$ monomer conversion. Yagci and co-workers have reported a co-initiation system, g- $\mathrm{C}_{3} \mathrm{~N}_{4}$ and triethylamine $\left(\mathrm{Et}_{3} \mathrm{~N}\right)$, which can photoinitiate the polymerization of methacrylates to afford a polymer with broad dispersity $(\nexists>2.0) .{ }^{27}$ Inspired by this study, we introduced the $\mathrm{g}-\mathrm{C}_{3} \mathrm{~N}_{4} /$ amine co-catalyst into our PET-RAFT system to speed up the deoxygenation and polymerization rates (Figure $1 \mathrm{c}$ shows the reaction setup). In the present system, the photo-activated $\mathrm{g}-\mathrm{C}_{3} \mathrm{~N}_{4}$ enables electron transfer (ET) from added TAs to dissolved molecular oxygen $\left(\mathrm{O}_{2}\right)$, providing a pathway for oxygen removal under irradiation of a suitable light source (Figure 1d). Furthermore, the ET can facilitate the activation of the TTC and hence drive the polymerization in the presence of a suitable monomer. Chain transfer to other TTCs can result in a dormant polymer chain and another propagating chain (i.e. the RAFT process, Figure 1d).

Firstly, we conducted the PET-RAFT polymerizations of methyl acrylate (MA) under UV light irradiation. In general, a mixture containing MA (100 equiv.), TTC-1 (1 equiv.), g$\mathrm{C}_{3} \mathrm{~N}_{4}$ (2.76 mg mL $\left.\mathrm{m}^{-1}\right)$, TEOA (6.7 equiv.) and DMSO (50\%, $\mathrm{v} / \mathrm{v})$ was combined in a vial sealed with septum and irradiated under the UV light source without any deoxygenation process.
The dispersed $\mathrm{g}-\mathrm{C}_{3} \mathrm{~N}_{4}$ was then removed from the reaction mixture by filtering through a filter head post-polymerization to afford a clear polymer solution for analysis. Kinetic investigations revealed high MA conversion ( $90 \%)$ within 5 hours with an induction period of $\sim 30 \mathrm{~min}$ (Figure $2 \mathrm{a}$, red line). Following such a short induction period, a linear dependence of $\ln \left([\mathrm{M}]_{0} /[\mathrm{M}]_{\mathrm{t}}\right)$ with irradiation time demonstrates the rate of the polymerization to be pseudo-first order with respect to monomer consumption. The apparent rate constant $\left(k_{\text {app }}\right)$ is calculated to be $0.533 \mathrm{~h}^{-1}$ (Table S1, Supporting information), which is even higher than that of a typical photo-RAFT polymerization deoxygenated by three freeze-pump-thaw cycles $\left(k_{\text {app }}=0.167\right.$ $\mathrm{h}^{-1}$, Table S1). This result demonstrates that the introduction of g- $\mathrm{C}_{3} \mathrm{~N}_{4}$ into PET-RAFT polymerization not only enables the efficient photo-removal of $\mathrm{O}_{2}$, but also significantly accelerates the photo-polymerization rate via the PET pathway. The theoretical molecular weights $\left(M_{\mathrm{n} \text { theo }}\right)$ were calculated based on ${ }^{1} \mathrm{H}$ NMR data (Figure S3, Supporting Information). The number average molecular weights $\left(M_{\mathrm{n}}\right)$ of PMA samples were characterized by GPC measurements (Figure $2 \mathrm{~b}$ ). The $M_{n, G P C}$ MWs increase linearly with conversion (as shown in Figure 2c) and the polymer dispersity $(\bigoplus)$ remained narrow $(\bigoplus<$ 1.20) throughout the reaction. It should be noted that the $M_{\mathrm{n}}$ GPC MWs are in close agreement to their calculated theoretical values, with differences ascribed to the different hydrodynamic volumes of PMA compared to the polystyrene standards used for calibration. The synthesized PMA also displayed good retention of $\alpha$ and $\omega$ end-groups at high monomer conversions, as evidenced by MALDI-ToF MS (Figure 2d-e). The high end group fidelity was also confirmed by ${ }^{1} \mathrm{H}$ NMR measurement on the purified PMA product (Figure S4).

Other control experiments were performed in which $\mathrm{g}-\mathrm{C}_{3} \mathrm{~N}_{4}$ or amine was selectively omitted (Figure 2a). Polymerization did occur in the absence of $\mathrm{g}-\mathrm{C}_{3} \mathrm{~N}_{4}$ with a long induction period of $>3$ hours and a low $k_{\text {app }}$ of $0.124 \mathrm{~h}^{-1}$ (Table S1). This isin good agreement with our previous report. ${ }^{13}$ This result also 

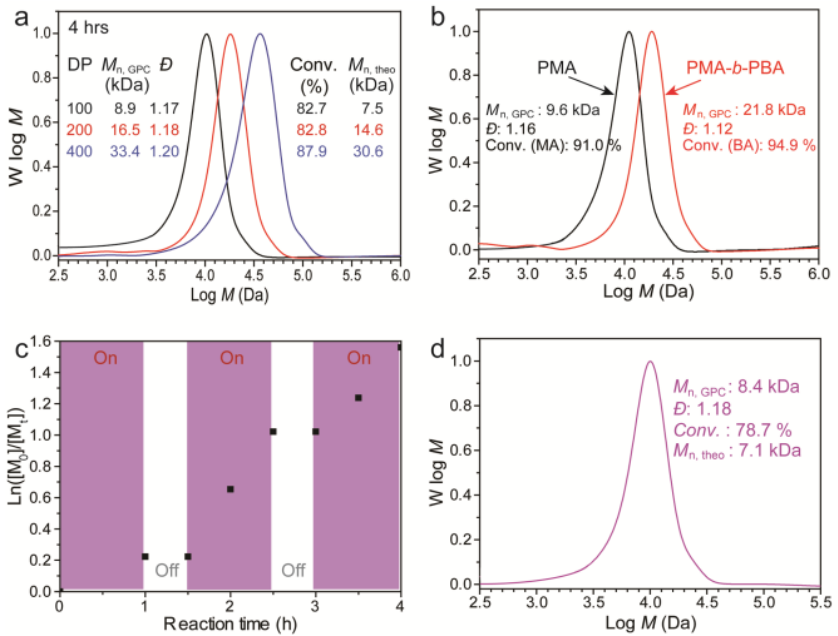

Figure 3. (a) PET-RAFT polymerizations of MA with different DPs (DP $=100,200$ and 400). (b) Synthesis of PMA- $b$ PBA diblock copolymers. (c) PET-RAFT polymerization of MA using TTC-1 with repeated "On/Off" cycling. (d) GPC profile of the PMA prepared in "On/Off” experiment.

reveals that although the TTC can be photo-activated, its contributions to the photo-reduction/polymerization are far less than that from the photo-catalyst, $\mathrm{g}-\mathrm{C}_{3} \mathrm{~N}_{4}$. Polymerization without the amine showed a significantly longer induction period ( $3 \mathrm{~h}$ vs. $30 \mathrm{~min}$, Figure $2 \mathrm{a}$ ), indicating the beneficial addition of TEOA to allow for efficient deoxygenation of the reaction mixture. Based on these results we can conclude that the $\mathrm{g}-\mathrm{C}_{3} \mathrm{~N}_{4}$ /amine catalytic system allows for good control over the PMA chain-growth process, enabling the facile preparation of PMA with precise molecular weight and low polymer dispersity without tedious deoxygenation procedures. All PMA products of these control experiments were further characterized by GPC measurements, showing similar molecular weight and narrow polymer dispersity (Figure S5).

Next, the formation of PMA of differing molecular weights was achieved by changing the targeted degree of polymerization (DP) and allowing the reaction to reach high monomer conversions. After 4 hours of irradiation, three different sizes of PMA (DP $=100,200$ and 400) were prepared with good agreement between the theoretical molecular weights and those observed via GPC measurements (Figure 3a). The GPC profiles of all PMAs were monomodal and symmetrical, indicating that the PET-RAFT polymerizations were still wellcontrolled even for the synthesis of PMA with chain length of $>350$ repeat units. By taking advantage of the high chain-end fidelity, we further prepared block copolymers via the presented PET- RAFT method. A PMA polymer was firstly prepared to give a starting homopolymer. After purification, the PMA product (1 equiv.) was re-dissolved in a DMSO solution containing BA (100 equiv.), $\mathrm{g}-\mathrm{C}_{3} \mathrm{~N}_{4}\left(2.76 \mathrm{mg} \mathrm{mL}^{-1}\right)$ and TEOA (6.7 equiv.). The mixture was irradiated under UV light for 8 hours without deoxygenation and the conversion of BA was calculated to be $94.9 \%$ by ${ }^{1} \mathrm{H}$ NMR analysis. The GPC profiles of the homopolymer (PMA) and its chain-extended product (PMA- $b$-PBA) are showed in Figure 3b. The block copolymer clearly shows a shift to the higher molecular weight region with very little tailing. This result combined with the ${ }^{1} \mathrm{H}$ NMR analysis (Figure S6), demonstrates the successful preparation of PMA- $b$-PBA copolymer and again confirms high end-group fidelity of the PMA macro-TTC.
The ability to achieve "On/Off" temporal control during the PET-RAFT polymerization was then investigated using intermittent light and dark exposure (Figure 3c). A mixture of TTC, MA, g- $\mathrm{C}_{3} \mathrm{~N}_{4}$, TEOA and solvent was exposed to the UV light, reaching $\sim 20 \%$ monomer conversion in the first hour of irradiation. This period is attributed to the combined durations of deoxygenation, induction and polymerization. After removal of the light source, complete cessation of polymerization was observed over a 30 minute period; then, re-exposure with the UV light allowed for resumed polymerization. This cycle could be repeated several times, indicating efficient activation and deactivation of the PET-RAFT system. After a total irradiation time of 3 hours the polymer product was isolated and fully characterized, showing high monomer conversion, controlled molecular weight and narrow polymer dipersity (conv. $=78.7 \%, M_{\mathrm{n} \mathrm{GPC}}=8.4 \mathrm{kDa}, \emptyset=1.18$, Figure $3 \mathrm{~d}$ ).

The $\mathrm{g}-\mathrm{C}_{3} \mathrm{~N}_{4}$ is used as photocatalyst in the PET-RAFT system. Thus, we investigated the effect of $\mathrm{g}-\mathrm{C}_{3} \mathrm{~N}_{4}$ concentration on the polymerization with the above described reaction setup (Figure 1c). As shown in Figure 4a-b, the success of the PETRAFT polymerization is achieved using all three different catalyst concentrations. Specifically, under the lowest concentration $\left(1.10 \mathrm{mg} \mathrm{mL}^{-1}\right)$, the photo-polymerization presents a prolonged induction period and a $k_{\text {app }}$ of $0.490 \mathrm{~h}^{-1}$ (Table S2, Supporting Information). For the case of higher catalyst concentrations (i.e. 2.76 or $5.52 \mathrm{mg} \mathrm{mL}^{-1}$ ), they show identical $k_{\text {app }}$ 's of $0.533 \mathrm{~h}^{-1}$ (Table S2), while the use of higher $\mathrm{g}-\mathrm{C}_{3} \mathrm{~N}_{4}$ concentration just allows for a shorter induction period. Based on this result, we can conclude that increasing the amount of g- $\mathrm{C}_{3} \mathrm{~N}_{4}$ can alter the induction period, but has minimal effect on the polymerization rate.

The TTCs with different molecular structures, specifically different leaving group (namely, R-group) structures have been reported to have an effect on the traditional RAFT polymerization. ${ }^{35}$ When TTCs having different R-group leaving abilities were employed, such as TTC-2 or TTC-3, we observed similar polymerization behaviours after 4 hours of irradiation, including similar induction period, $k_{\text {app }}$, monomer conversion, molecular weight and polymer dispersity compared to that in the case using TTC-1 (Figure 4c-d, Table S2 and Figure S7). This result thus reveals that different TTCs employed in this study have minimal effects on the PETRAFT polymerization. This is in good agreement with our previous studies, ${ }^{31,36}$ in which the R-group only affect the initiation process of photo-RAFT systems, because as soon as one monomer unit is added the end-group structure becomes almost indistinguishable. We also successfully conducted PET-RAFT polymerization of an acrylamide monomer $(N, N$ dimethylacrylamide, DMA) using TTC-1 in DMSO. A PDMA polymer was prepared with a DMA conversion of $65.6 \%$ and after 4 hours of irradiation (Figure S8).

As above discussed, it was of interest to ascertain if the PET-RAFT system is as effective in a non-polar organic solvent, such as toluene. As shown in Figure 4e-f, the employed solvent appears to have an effect on the $k_{\text {app }}$, while the polymer dispersity of the furnished PMA products is almost identical. Namely, the PET-RAFT polymerization conduced in toluene has a prolonged induction period of $>1$ hour and a $k_{\text {app }}$ of $0.480 \mathrm{~h}^{-1}$ (Table S2). We may theorize that the ET process to generate the ion-pair prior to fragmentation of the TTC radical anion will be enhanced by the stabilizing effect a polar solvent would have on the ionic species in solution. In addition, all PMA products were characterized by GPC (Figure $4 \mathrm{~b}, 4 \mathrm{~d}$ and 

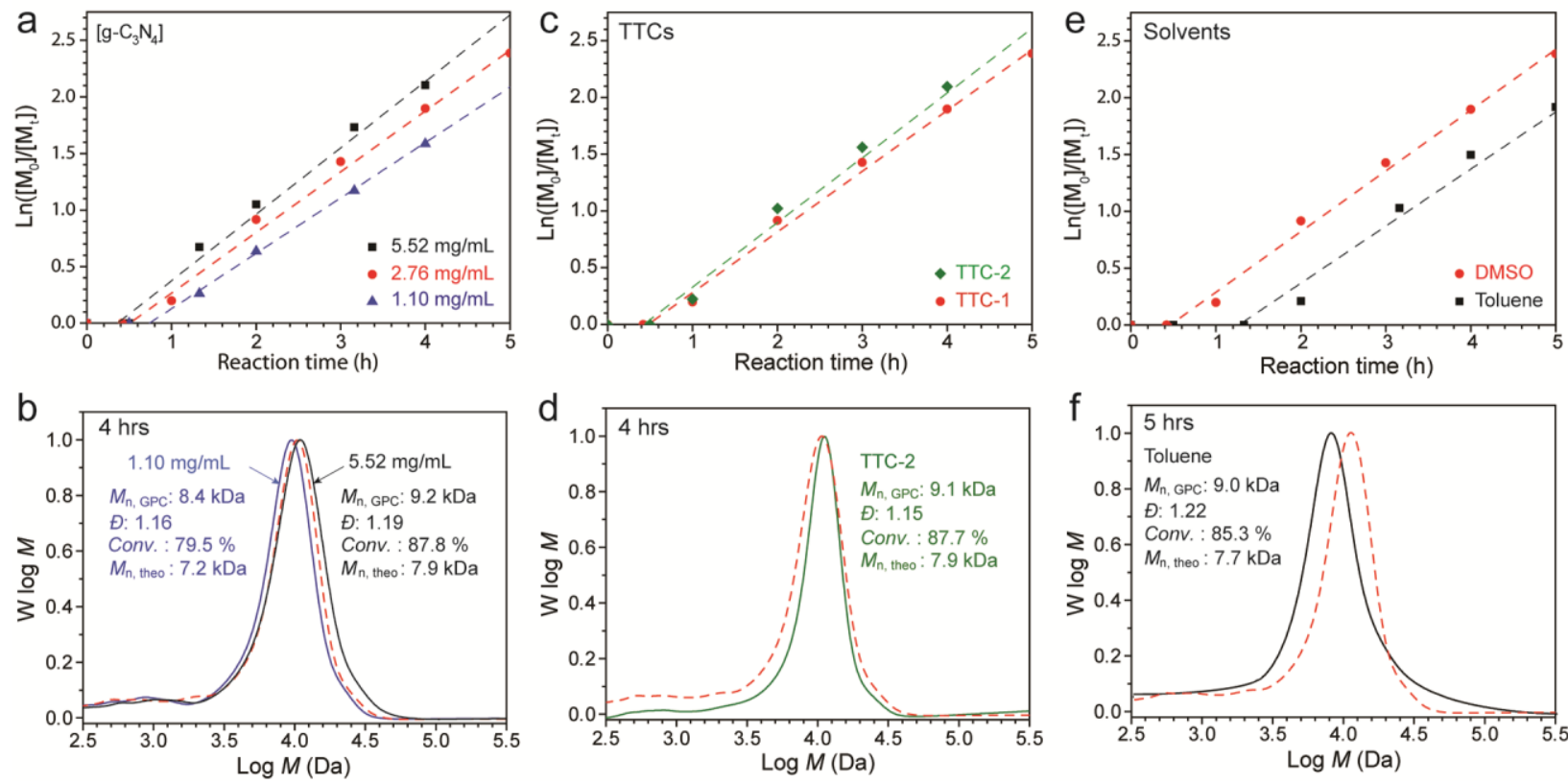

Figure 4. Investigations on the PET-RAFT polymerization of MA using (a-b) different amount of g- $\mathrm{C}_{3} \mathrm{~N}_{4}$, (c-d) different TTCs and (e-f) different solvents. The red lines represent the PMA obtained using TTC-1 and $g-\mathrm{C}_{3} \mathrm{~N}_{4}$ in DMSO $\left(\left[\mathrm{g}-\mathrm{C}_{3} \mathrm{~N}_{4}\right]=2.76 \mathrm{mg} \mathrm{mL}^{-1}\right)$.

4f) and ${ }^{1} \mathrm{H}$ NMR measurements, displaying controlled molecular weights and narrow polymer dispersities $(\bigoplus \leq 1.22)$.

Generally, fresh monomers are stored in amber bottles with inhibitor (for the case of MA, 100 ppm 4-methoxyphenol, MEHQ) at low temperature for lab use. Therefore, fresh monomers are required to be purified prior to most polymerization experiments. Encouraged by the success in using g-C3N4 as a photo-catalyst to reduce $\mathrm{O} 2$, we conducted PET-RAFT polymerization of non-purified MA under identical reaction conditions as above. Surprisingly, the kinetic study shows the characteristics of a typical "living" polymerization: namely, pseudo-first order kinetics with regards to monomer conversion increasing linearly as a function of irradiation time (Figure 5a). A prolonged induction period ( $\sim 1$ hour) and a slightly lower $k_{\text {app }}\left(0.405 \mathrm{~h}^{-1}\right.$, Table S3 in Supporting Information) were observed in comparison with that of polymerization using purified monomer. Although the polymerization mechanism is not yet clear, it has been demonstrated that controlled RDRP can be achieved in the presence of inhibitors. For example, Percec and co-workers have reported a coppercatalyzed RDRP of MA in the presence of MEHQ without compromising the structure of the final polymer. ${ }^{37}$ After 4 hours of irradiation, PMA polymer was obtained with narrow polymer dispersity $(Ð \sim 1.15)$ at high MA conversion $(\sim 75 \%$, Figure 5b). A fundamental key to the success of any RDRP is chain-end fidelity and hence it was critical to determine chainend fidelity in this reaction. The synthesized PMA displayed relatively good retention of $\alpha$ and $\omega$ end-groups even at $75 \%$ MA conversion, as evidenced by MALDI-ToF MS (Figure 5cd). The MALDI-ToF MS show a single monomodal series with clear background, indicating a uniform chemical structure of the obtained PMA product from non-purified monomer. More importantly, there is no emission-absorption overlap observed with the peak emission at $\sim 365 \mathrm{~nm}$ from the light source (Figure S9, Supporting Information). Therefore, we believe that the reduced apparent propagation rate constant and the longer inhibition period cannot be attributed to the absorption of MEHQ.

We further conducted a PET-RAFT polymerization of MMA using a dithiobenzoate (2-cyano-2-propyl benzodithioate) as chain transfer agent. As shown in Figure S10, the photo-polymerization shows a prolonged induction period of 3.5 hours and a much lower kapp of $0.082 \mathrm{~h}^{-1}$ (Table S4, Supporting Information). After a total irradiation time of 18 hours the polymer product was isolated and fully characterized, showing a controlled molecular weight and narrow polymer dipersity (conv. $=70.2 \%, M_{\mathrm{n} \mathrm{GPC}}=7.6 \mathrm{kDa}, \emptyset=1.17$ ). The lower $k_{\mathrm{app}}$ is considered to be attributed to the slower propagation rate of methacrylate monomers.
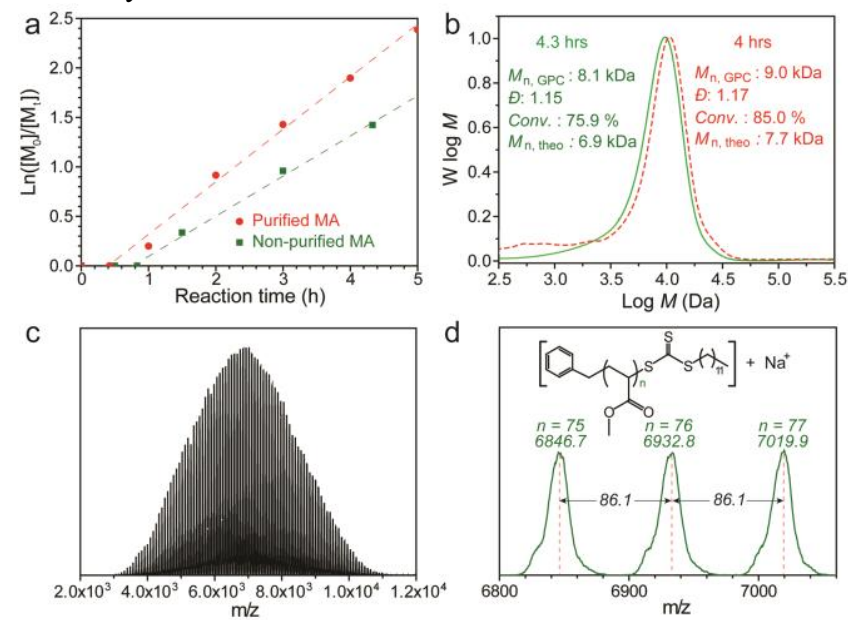

Figure 5. Characterization of PMA prepared by PET-RAFT polymerization of MA with inhibitor: (a) kinetic study, (b) GPC profile, and (c-d) MALDI-ToF-MS analysis.

\section{CONCLUSION}

In conclusion, we have reported a metal-free PET-RAFT polymerization by utilizing the photo-active properties of $\mathrm{g}$ - 
$\mathrm{C}_{3} \mathrm{~N}_{4}$. Photo-polymerizations performed in the presence of oxygen and/or inhibitors are controlled and yield polymer products with controlled molecular weights, low polymer dispersity and good chain-end fidelities. The accessibility of the end-groups was confirmed by chain extension experiments. Negligible polymerization in the absence of light confers temporal "ON/OFF" control of the PET-RAFT process. The organocatalyst $\mathrm{g}-\mathrm{C}_{3} \mathrm{~N}_{4}$ presents advantages over conventional inorganic photo-catalysts, metal-catalysts, and dye sensitizers, including its low toxicity, facile synthesis, "earth-abundant" nature, simple removal post-polymerization, and compatibility with a variety of functional groups, monomers, TTCs and solvents. This study thus opens up a new avenue for the use of g$\mathrm{C}_{3} \mathrm{~N}_{4}$ in the controllable RDRP applications.

\section{ASSOCIATED CONTENT}

Supporting Information. The detailed characterization on g$\mathrm{C}_{3} \mathrm{~N}_{4}$ along with ${ }^{1} \mathrm{H}$ NMR spectra and GPC chromatograms of polymers synthesized in this study are available in the Supporting Information. This material is available free of charge via the Internet at http://pubs.acs.org.

\section{AUTHOR INFORMATION}

\section{Corresponding Author}

*E-mail: gregghq@unimelb.edu.au; junwang.tang@live.ucl.ac.uk

\section{Notes}

The authors declare no competing financial interests.

\section{ACKNOWLEDGMENT}

The authors acknowledge financial support from the Australian Research Council via the Discovery Project scheme (DP170104321, G. G. Q). A. R. is supported by the Melbourne International Research Scholarship (MIRS) and the Melbourne International Fee Remission Scholarship (MIFRS).

\section{REFERENCES}

1. Ligon, S. C.; Husár, B.; Wutzel, H.; Holman, R.; Liska, R. Chem. Rev. 2014, 114, (1), 557-589.

2. Jakubowski, W.; Matyjaszewski, K. Angew. Chem. Int. Ed. 2006, 45, (27), 4482-4486.

3. Konkolewicz, D.; Wang, Y.; Zhong, M.; Krys, P.; Isse, A. A.; Gennaro, A.; Matyjaszewski, K. Macromolecules 2013, 46, (22), 8749-8772.

4. Oytun, F.; Kahveci, M. U.; Yagci, Y. J. Polym. Sci., Part A: Polym. Chem. 2013, 51, (8), 1685-1689.

5. Chapman, R.; Gormley, A. J.; Herpoldt, K.-L.; Stevens, M. M. Macromolecules 2014, 47, (24), 8541-8547.

$6 . \quad \mathrm{Xu}, \mathrm{J}$.; Jung, K.; Boyer, C. Macromolecules 2014, 47, (13), 4217-4229.

$7 . \quad$ Corrigan, N.; Rosli, D.; Jones, J. W. J.; Xu, J.; Boyer, C. Macromolecules 2016, 49, (18), 6779-6789.

8. Li, J.; Ding, C.; Zhang, Z.; Pan, X.; Li, N.; Zhu, J.; Zhu, X. Macromol. Rapid Commun. 2017, 38, 1600482.

9. Shanmugam, S.; Xu, J.; Boyer, C. Macromolecules 2016, 49, (24), 9345-9357.

10. Wang, J.; Rivero, M.; Bonilla, A. M. o.; SanchezMarcos, J.; Xue, W.; Chen, G.; Zhang, W.; Zhu, X. ACS Macro Lett. 2016, 5, 1278-1282.
11. Yang, Q.; Lalevée, J.; Poly, J. Macromolecules 2016, 49, 7653-7666.

12. Shanmugam, S.; Xu, J.; Boyer, C. Macromolecules 2017, 50, (5), 1832-1846.

13. Fu, Q.; Xie, K.; McKenzie, T. G.; Qiao, G. G. Polym. Chem. 2017, 8, (9), 1519-1526.

14. Reyhani, A.; McKenzie, T. G.; Ranji-Burachaloo, H.; Fu, Q.; Qiao, G. G. Chem. Eur. J. 2017, 23, (30), 7221-7226.

15. Fu, Q.; Kim, J.; Gurr, P. A.; Scofield, J. M. P.; Kentish, S. E.; Qiao, G. G. Energy Environ. Sci. 2016, 9, (2), 434-440.

16. Nguyen, N. H.; Percec, V. J. Polym. Sci., Part A: Polym. Chem. 2011, 49, (22), 4756-4765.

17. Yeow, J.; Shanmugam, S.; Corrigan, N.; Kuchel, R. P.; Xu, J.; Boyer, C. Macromolecules 2016, 49, 7277-7285.

18. Xu, J.; Jung, K.; Corrigan, N. A.; Boyer, C. Chem. Sci. 2014, 5, (9), 3568-3575.

19. Xu, J.; Shanmugam, S.; Duong, H. T.; Boyer, C. Polym. Chem. 2015, 6, (31), 5615-5624.

20. Chapman, R.; Gormley, A. J.; Stenzel, M. H.; Stevens, M. M. Angew. Chem. Int. Ed. 2016, 128, (14), 4576-4579.

21. Ong, W.-J.; Tan, L.-L.; Ng, Y. H.; Yong, S.-T.; Chai, S.-P. Chem. Rev. 2016, 116, (12), 7159-7329.

22. Liu, Y.; Zhang, X.; Wang, J.; Yang, P. Phys. Chem. Chem. Phys. 2016, 18, (46), 31513-31520.

23. Martin, D. J.; Qiu, K.; Shevlin, S. A.; Handoko, A. D.; Chen, X.; Guo, Z.; Tang, J. Angew. Chem. Int. Ed. 2014, 53, 9240-9245.

24. Zheng, Y.; Liu, J.; Liang, J.; Jaroniec, M.; Qiao, S. Z. Energy Environ. Sci. 2012, 5, (5), 6717-6731.

25. Zheng, Y.; Lin, L.; Ye, X.; Guo, F.; Wang, X. Angew. Chem. Int. Ed. 2014, 53, (44), 11926-11930.

26. Friedmann, D.; Hakki, A.; Kim, H.; Choi, W.; Bahnemann, D. Green Chem. 2016, 18, (20), 5391-5411.

27. Kiskan, B.; Zhang, J.; Wang, X.; Antonietti, M.; Yagci, Y. ACS Macro Lett. 2012, 1, (5), 546-549.

28. Dadashi-Silab, S.; Tasdelen, M. A.; Kiskan, B.; Wang, X.; Antonietti, M.; Yagci, Y. Macromol. Chem. Phys. 2014, 215 , 675-681.

29. Martin, D. J.; Qiu, K.; Shevlin, S. A.; Handoko, A. D.; Chen, X.; Guo, Z.; Tang, J. Angew. Chem. Int. Ed. 2014, 53, (35), 9240-9245.

30. Martin, D. J.; Reardon, P. J. T.; Moniz, S. J. A.; Tang, J. J. Am. Chem. Soc. 2014, 136, (36), 12568-12571.

31. McKenzie, T. G.; Fu, Q.; Wong, E. H. H.; Dunstan, D. E.; Qiao, G. G. Macromolecules 2015, 48, (12), 3864-3872.

32. Xu, J.; Jung, K.; Atme, A.; Shanmugam, S.; Boyer, C. J. Am. Chem. Soc. 2014, 136, (14), 5508-5519.

33. Fu, Q.; McKenzie, T. G.; Tan, S.; Nam, E.; Qiao, G. G. Polym. Chem. 2015, 6, (30), 5362-5368.

34. Fu, Q.; McKenzie, T. G.; Ren, J. M.; Tan, S.; Nam, E.; Qiao, G. G. Sci. Rep. 2016, 6, 20779.

35. Moad, G.; Rizzardo, E.; Thang, S. H. Aust. J. Chem 2012, 65, 985-1076.

36. McKenzie, T. G.; Wong, E. H. H.; Fu, Q.; Sulistio, A.; Dunstan, D. E.; Qiao, G. G. ACS Macro Lett. 2015, 4, (9), 10121016.

37. Lligadas, G.; Percec, V. J. Polym. Sci., Part A: Polym. Chem. 2008, 46, (10), 3174-3181. 
SYNOPSIS TOC: The metal-free semiconductor graphitic carbon nitride $\left(\mathrm{g}-\mathrm{C}_{3} \mathrm{~N}_{4}\right)$ was introduced into RAFT polymerization for the first time. The production of acrylate and acrylamide polymers has been achieved via a PET-RAFT polymerization using $\mathrm{g}_{-} \mathrm{C}_{3} \mathrm{~N}_{4}$ as a photoactive organocatalyst without prior deoxygenation. The resulting polymers display narrow molecular weight distributions, controlled molecular weights, and high end-group fidelity as exemplified by ${ }^{1} \mathrm{H}$ NMR analysis, MALDI-TOF-MS measurement and chain extension experiment. Temporal control is illustrated by intermittent light and dark cycles, with polymer growth arrested in the absence of irradiation. The effects of changing RAFT agents (i.e. trithiocarbonates), solvents, catalyst concentrations and degrees of polymerization in this system have been investigated. The successful polymerization of a non-purified monomer demonstrates the robust nature of the presented PET-RAFT method.

Insert Table of Contents artwork here

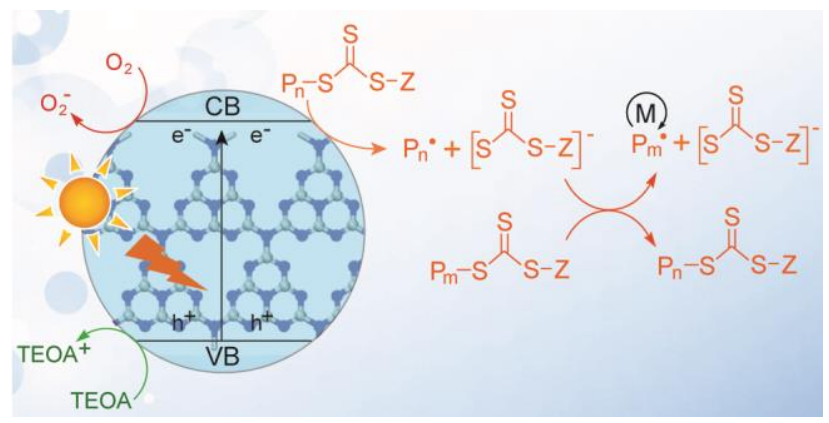

